\title{
New Technologies for Rural Lighting in Developing Countries: White LEDs
}

\author{
Adoniya Ben Sebitosi, Member, IEEE, and Pragasen Pillay, Fellow, IEEE
}

\begin{abstract}
Most of the third-world rural areas, especially in subSaharan Africa, are still without electricity. The few existing offgrid and upcoming installations are remote and characterized by limited resources that call for drastic conservation measures. For the majority of these emerging consumers, lighting is the priority load. Rural electrical lighting load models are characterized by inaccuracies due to technical omissions, highlighted in this paper, and result in energy wastage. Solutions to the third-world problems need not follow similar paths to those of the developed world. In fact, cutting-edge technologies like the cell phone have already leapfrogged rural communications where expensive infrastructure had been perennially cited as the impediment. In this paper, another futuristic technology, the white light emitting diode (LED), for general lighting, is poised to create yet another revolution in African rural electrification.
\end{abstract}

Index Terms-Efficacy, energy conservation, light load modeling, lumens, rural areas, white LEDs.

\section{INTRODUCTION}

$\mathbf{T}$ HE BULK OF sub-Saharan Africa is still not electrified. The national power utilities in these countries are struggling to cope with the existing infrastructure, which are actually shrinking, in real terms. As a result, the current trend is for communities to fend for themselves. Small remote power installations, especially from renewable energy are characterized by limited generation and storage capacities. These resource constraints call for effective demand side management that conserves energy but with minimal compromise on service delivery quality.

In these communities, lighting is provided by smoky kerosene lamps and candles, which is responsible for perennial respiratory and sight illnesses, in addition to contributing to the missed learning, business, and other opportunities. This makes lighting an activity of priority in rural electrification. Globally, electric lighting accounts for about one fifth of all electric energy consumed, and a similar percentage of electric energy related green house gas (GHG) emissions. Therefore, any efficient electric lighting initiative is a subject of interest for all humankind.

Lighting loads are often inaccurately modeled due to the omission of a number of relevant nonelectrical parameters. Illumination as a technology has made its own independent advances that must be included in the ultimate electrical lighting solutions [1]-[5]. High benefits of lighting in the work place,

Manuscript received July 28, 2006; revised May 9, 2004. Paper no. TEC00189-2005.

A. B. Sebitosi is with the University of Cape Town, Rondebosch 7701, South Africa.

P. Pillay is with the Department of Electrical and Computer Engineering, Clarkson University, Potsdam, NY 13699 USA (e-mail: pillayp@clarkson.edu).

Digital Object Identifier 10.1109/TEC.2006.888024 for example, optimizes sight-dependent tasks while minimizing the energy used. Illumination experts [6], [7] point out that overlighting a space or task area degrades the lighting quality in addition to wasting energy.

Solutions for electrification or energy development in the developing world need not follow the same path as followed in the developed world. Instead, relevant technical solutions for advanced applications in the developed world can be used to leapfrog intermediate technologies and applied directly, with benefits to the developing countries. One example is the use of cell phones, which do not require the costly physical infrastructure of regular land phones. Very remote rural locations that would have otherwise not dreamt of getting any communication are now just a pushbutton away from the rest of the world.

In the field of lighting, recent developments in automotive electronics may yet launch another cutting-edge technology into the rural communities. The red light-emitting diode (LED) in the traffic and car tailight industries in North America reported a market penetration of $20 \%$, rising from a mere $8 \%$ during an 18-month period leading up to 2002. Energy savings of up to $80 \%$ were reported. This LED is fast evolving into the white LED for general lighting, and may be applied directly to rural electrification problems.

This paper examines the lighting issue in depth. Section II has a description of how radiometric power output of a light source (in watts) relates to photometric or light power (in lumens) by incorporating the human eye frequency response. A range of attributes of a light source is described. How they contribute to the lighting quality, and thus, finally, impact on the electric power source is explained. Section III compares the energy consumption and cost of incandescent light souces versus LED light sources. Section IV discusses briefly the past and present of technological issues in the fabrication of the LED. Section V is a brief summary of the projected future of the LED. Conclusions are then drawn on the possible impact of LEDs on rural electrification.

\section{BACKGROUND: LIGHTING LOAD MODELING}

When connected across a voltage source, an incandescent light bulb draws a current with a waveform that is a near replica of (and in phase with) the voltage, and therefore, at a near unity power factor. This is the classic criterion for an ideal electric load, yet this, apparently, ideal load is labeled as inefficient: in fact, very inefficient.

Modeling lighting loads is unique as it involves the human eye as the ultimate load determining the required electric power input. Any energy losses prior to reaching the eye constitute power delivery losses, and failure by light to reflect off an 


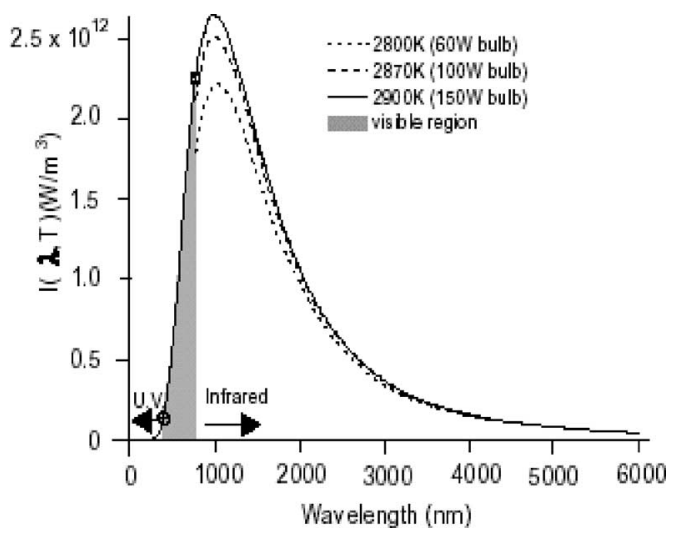

Fig. 1. Output energy as a function of wavelength for an incandescent tungsten bulb.

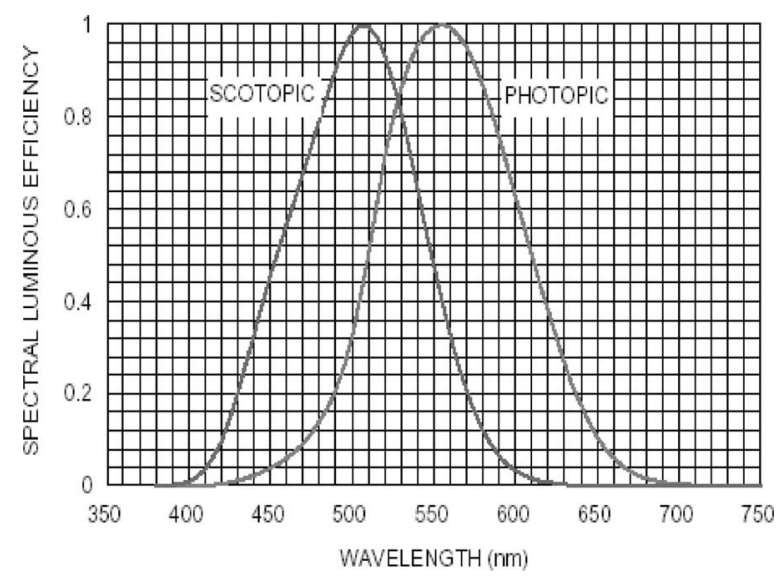

Fig. 2. Human eye response plotted against wavelength.

intended target, and then, to the reception by a normal eye constitutes system inefficiency.

In Fig. 1, the curve represents the radiometric output power (in watts) of a tungsten incandescent light source as a function of wavelength. The shaded area represents the visible output of the source, defined as the range from 360 to $830 \mathrm{~nm}$. This fraction determines the efficacy of the light source. However, since the human eye responds differently to different wavelengths (within the visible range), the light source efficacy is not (literally) the shaded area divided by the total area.

Fig. 2 is an empirical curve, drawn by the International Commission on Illumination (CIE), of an average human eye response as a function of wavelength. This is the photopic curve. (The scotopic curve is the response during very low light levels and is not part of this illustration.)

As seen on the photopic function, the human eye responds best at $555 \mathrm{~nm}$. This point defines the full coefficient, 1, of the eye's response. The unit of light power is the lumen $(\mathrm{lm})$. The eye receives light in radiometric watts and interprets them in lumens using the response function. For example, $1 \mathrm{~W}$ of (monochromatic) radiometric power at $500 \mathrm{~nm}$ will be interpreted, in lumens, as 0.3 in value compared to $1 \mathrm{~W}$ at $555 \mathrm{~nm}$ (see Fig. 2).
The following is a simple illustration of a general monochromatic case. The symbols used are not the authentic illumination symbols but merely serve to illustrate a point.

Let $y_{1}=f_{1}(\lambda) \mathrm{W}$, represent the radiometric function (due to the light source) in Fig. 1 (where $\lambda$ is the wavelength). And $y_{2}=f_{2}(\lambda)$, represent the photopic function (of the human eye) in Fig. 2.

Then, the light power $L_{r}$ (in lumens) of a monochromatic radiation of wavelength $\lambda_{r}$ is given by

$$
L_{r}=K f_{1}\left(\lambda_{r}\right) f_{2}\left(\lambda_{r}\right) \operatorname{lm} \text {. }
$$

The constant $K=683$ is the watt-lumen conversion constant. A lumen can then be defined as the (visual) power of monochromatic radiation of frequency $540 \times 10^{12} \mathrm{~Hz}$ (which is $555 \mathrm{~nm}$ in air or vacuum) equal to $683^{-1} \mathrm{~W}$.

The conversion of radiometric power of a general nonmonochromatic light source to luminous quantity, however, involves a lot of other illumination functions that are beyond the scope of this illustration. Fortunately, light source manufacturers normally indicate the efficacies (in lumen per watt) of their products.

\section{LIGHT SOURCE PERFORMANCE}

As mentioned, efficacy is given as the number of lumens of light output of a light source per input watt of electrical power (lumen/watt). However, this is just one of the indices of lighting quality. For a more comprehensive light source design one requires more data. Initially, the task for which light is required must be defined and the required amount of light quantified.

As an example, one may consider an incandescent light source and an LED, which have practically the same lumens per watt (efficacies) rating. It would therefore be reasonable to assume that the two light sources would consume the same amount of energy to perform the same task. How then could the traffic and signal lights industry report such massive energy savings of up to $80 \%$ by just replacing the incandescent light sources with LEDs?

In the case of a "stop" traffic light, for example, the required task is the production of red light just for the view of the car driver. The keywords are color and directivity. True efficiency must therefore be the amount of power successfully converted for the task per unit watt of input electric power.

In order to perform this task, the incandescent light source must use a reflector and a red filter. A 140-W incandescent lamp with an efficacy of $15 \mathrm{~lm} / \mathrm{W}$ will produce $2100 \mathrm{~lm}$, but after the red filtering and reflection, the amount of red light that is finally available to the driver may be only $200 \mathrm{~lm}$, which happens to be adequate. A red LED, on the other hand, is a monochromatic device and has directivity with an appropriate angle. It is task-specific; requiring neither filter nor reflector. Therefore, a replacement LED assembly for the same traffic light function only requires $200 \mathrm{~lm}$. Having the same efficacy as the incandescent light source. The LED ends up consuming only $10 \%$ of the power. Moreover, the LED has other superior attributes like shock resistance-a problem that causes premature failure in incandescent traffic lights and vehicle taillights.

Light sources have a variety of other attributes in varying degrees, as illustrated in the Appendix. These determine the 
suitability, and therefore, efficiency of a light source for a given task. In addition, the color of the surroundings having unique reflective properties will affect the amount of light required, and ultimately, impact on the required generation and/or storage capacity in an electrification design. "In some cases, enhancement of these influencing factors can improve performance without the need to raise illuminance." [2]

As mentioned earlier in the case of traffic lights, confining light to a specific purpose does improve energy efficiency. Philips engineers have also demonstrated the effectiveness of this technique, called "tasking." A set of specially constructed LED streetlights performed at par with sodium lamps despite the overwhelmingly superior efficacy of the latter.

If a light source is used for reading, it would appear reasonable to infer that energy would be most conserved if the light were confined to a target area, namely the book. Illumination experts, however, caution that this may cause discomfort due to glare [4] if the background is pitch dark. Other symptoms include annoyance and reduced productivity. Some mild ambient lighting, of the order of at least $10 \%$, which would otherwise be inadequate on its own, is recommended [6].

Finally, there are special circumstances that call for higher lumen levels of lamp than would be required ordinarily. These include provision for visually impaired persons or special age groups of occupants.

\section{SOLID-STATE LiGHTING (SSL)}

SSL has taken a foothold and is certain to revolutionize lighting energy consumption. Cynics refer to traditional electrical lighting as a process of heating of a medium by the application of electricity until it is hot enough to give out some light. A grossly energy-squandering scenario!

In contrast, LED technology involves a quantum process to convert dc current to light. Conversion efficiencies nearing $100 \%$ have been achieved in laboratory results with certain materials. Having said that, it should be pointed out that the LED has the same common $\mathrm{p}-\mathrm{n}$ junction heat dissipating characteristics. In order to realize more brightness, the dc forward current must be increased, which in turn increases the p-n junction temperature. Overrating the temperature can compromise the lifespan of a device. So, in order to realize sustainable brighter output, manufacturers are using higher thermally conductive lead frames and higher temperature epoxies in addition to higher efficiency semiconductor materials. The mounting of components on heat sinks further augments these with low thermal resistance. Then, there is the issue of light extractability that is still another stumbling block. In fact, it would appear that the materials with the most efficient quantum conversions have the poorer extractability efficiencies. These form topics which are addressed in research and should be awaited for with much anticipation by the African rural communities.

Historically, the LED efficacy has been doubling with every 18-24 months since the beginning of the 1970s. Such evolution is highly dependent on funding. In July 2001, the U.S. Senate launched, "the Next-Generation Lighting Initiative" with an ambitious goal to achieve $25 \%$ market penetration by the year

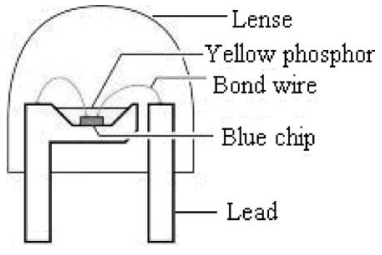

Fig. 3. Anatomy of a phosphor-based white LED.

2012. Subsequently, a bill was passed in April 2002, committing over a billion dollars per year for research and development (R\&D) for the next generation of lighting technologies.

LEDs have superior lifespans compared to incandescent light sources. However, like other light source types they suffer from lumen depreciation and one has to exercise caution with hyped figures like $100000 \mathrm{~h}$ [8]-[10]. This gradual deterioration, once understood, could be factored into scheduled maintenance. Unlike the abrupt failures by incandescent and fluorescent lamps it would be an added advantage. The time it takes to start a light source can, in certain instances, be important. Currently, compact fuorescent lamps (CFLs) are very popular in off-grid systems. There is a time delay to get to full brightness. So, the incandescent lamp still ends up standing in for that odd function like closet lighting. The LEDs are not only as fast as the incandescent light sources to start but even faster when going off.

White light from an LED is obtained in several ways. The resulting "whiteness" will vary depending on the method and material combination used (among other factors). In illumination terminology, these various tints are referred to as chromaticity points defined by pairs of $x-y$ coordinates on the CIE-1931 diagram [11]. One method of generating white light is by the converging of beams (of primary colors) from three monochromatic chips of red, green, and blue. This is theoretically the most accurate method (especially with color rendering) but in practice is still riddled with calibration problems.

A second method involves the use of monochromatic ultraviolet (UV) light generated by a single chip to excite three phosphors of red, green, and blue. The method is particularly discouraged due to a possibility of leaking UV light to the user. The color (or whiteness) is also said to be angle dependent. The third, and currently the most preferred method (and credited to [12]), is illustrated in Fig. 3. It involves a monochromatic blue light emitting gallium nitride chip (GaN) (typically at $265 \mathrm{~nm}$ ) that is coated with yttrium aluminium garnet (YAG), a yellow fluorescent phosphor. The yellow phosphor is excited by the blue light to produce a broad emission spectrum, in a process somewhat analogous to the fluorescent tube light.

Fig. 4 illustrates a typical emission spectrum of a phosphorbased white LED. Conversion efficiencies are dependent on the quality of the phosphor and the composition of YAG can be varied to generate a variety of chromaticity points. The phosphorescence typically peaks at about $555 \mathrm{~nm}$ with a color rendering index (CRI) of 85 , and is hence, a reasonable mimic of white light. Additionally, the chromatic performance of a phosphor-based white LED will be affected by the drive current and component age. However, in apparent acknowledgement of 


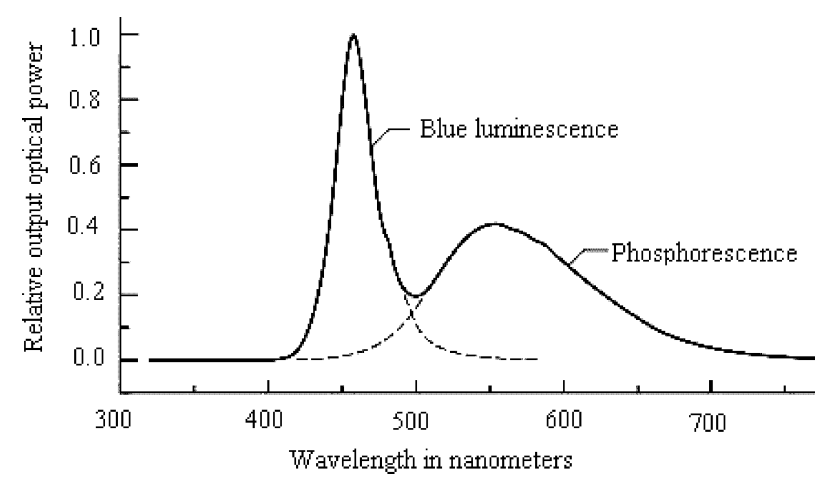

Fig. 4. Typical emission spectrum for a phosphor based white LED.

the transitional nature of the technology many applications (like automotive lights) have specs that permit some flexibility on chromaticity.

A possibility that future color mixing may be managed externally by waveguiding optical luminaires using light from several monochromatic chips has been raised in [13].

\section{RURAL Lighting REQUiREMENTS}

In Kenya, as in most sub-Saharan African countries, the overwhelming majority of the populations live in the rural areas with official grid electrification close to $1 \%$ or virtually nonexistent electrification. Current privatization trends of public corporations have led to further divestiture from the rural areas and dashing many hopes for further grid extensions. As a result, recent developments have been mainly driven by self-help initiatives. The available means to harness the all-vital electric energy are small and costly. All efforts must be made to economize the meager resources without compromising quality of service. The efficacies of household-incandescent lamps average at about $15 \mathrm{~lm} / \mathrm{W}$ and white LEDs are of the order of $25 \mathrm{~lm} / \mathrm{W}$.

In South Africa, a code of practice [6] gives the minimum lux for a whole range of locations and activities. For example, kitchens are allocated 200 lux, bathrooms are allocated 100 lux, and 500 lux is allocated for study and reading. Like other standards, there may be variations from country to country. In the following illustration, the specification of the South African Bureau of Standards will be assumed.

An incandescent lamp and a white LED for reading are compared below. If the reading area is $0.25 \mathrm{~m}^{2}$ and the required light density is $500 \mathrm{~lm} / \mathrm{m}^{2}$, then the lamp should give

$$
500 \times 0.25=125 \mathrm{~lm} .
$$

As of 14th April 2002, Lumileds produced LUXEON-5W, a 120-1m white LED light source with a power consumption of $5 \mathrm{~W}$. As mentioned earlier, LEDs have directivity and it is reasonable to assume that all the light can be confined to the required area.

The incandescent lamp will use a reflector (luminaire) to attain the directivity. A good quality luminaire has a coefficient of utilization (CU) of 0.55 [6]. $\mathrm{CU}$ is the indication of the proportion of useful light emitted by a luminaire. Therefore, in

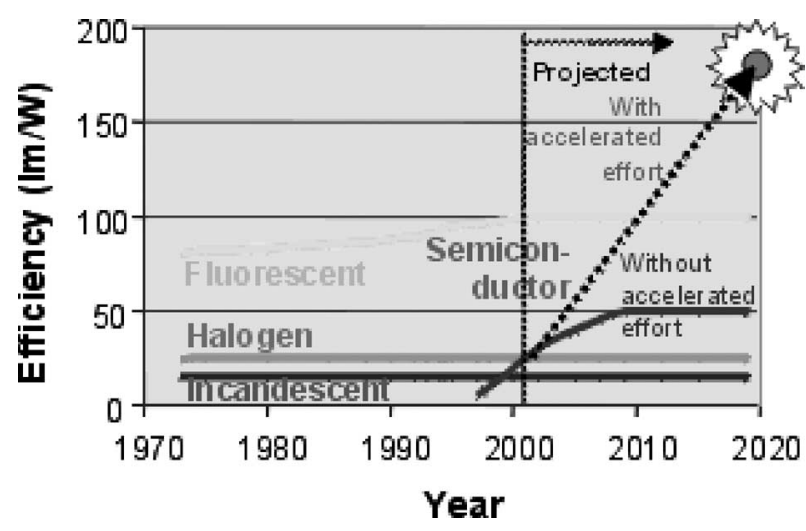

Fig. 5. Sandia National Laboratories projection model of the future of general lighting.

order to create the same effect as the Luxeon- 5 the incandescent light must produce $120 / 0.55=218 \mathrm{~lm}$. The efficacy of a typical incandescent lamp is $15 \mathrm{~lm} / \mathrm{W}$. The wattage of this lamp will be $218 / 15=14.5 \mathrm{~W}$. Incandescent lamp efficacies rise with filament temperature that in turn rises with lamp wattage. So, in reality a lamp of such low wattage will have an efficacy closer to $10 \mathrm{~lm} / \mathrm{W}$. This will make its wattage close to $20 \mathrm{~W}$, and hence, will require four times the amount of power as the Luxeon-5.

\section{FUTURE}

As of 2002, the commercial white LED had reached an efficacy mark of $25 \mathrm{~lm} / \mathrm{w}$. According to Sandia National Laboratories the projected efficacy for the white LED before the end of this decade is $50 \mathrm{~lm} / \mathrm{W}$ with a possibility of nearing 100 with accelerated effort [14], [15]. According to the projection model in [14] the accelerated track option is conditional upon adequate funding (see Fig. 5).

On the 25th of April, 2002 the U.S. Senate passed bill S.517, and committed over 1 billion US dollars per annum for R\&D, for "such areas as next-generation lighting technologies." This is a cause for optimism. The same forecast projects that at $50 \mathrm{~lm} / \mathrm{W}$ the per kilo lumen price will still be U.S. \$ 8.30 against the incandescent lamp's current U.S. \$ 0.56. Cost is, by far, the major disadvantage of the LED. If the accelerated track should be followed a price breakthrough of U.S. \$ 0.50 is projected at $120 \mathrm{~lm} / \mathrm{W}$ of component efficacy.

It should be noted that the Sandia model focused on efficacy as the major index for market response. There are other possibilities. The market could, for example, be impressed by other improving attributes like the lifespan or CRI and realize a price breakthrough much earlier.

The directivity attribute has been hitherto highlighted as a major efficiency factor for tasking and signals applications. However, for uniform and homogeneous lighting applications, the nature of LEDs being point sources presents a challenge. Moreover, manufacturers continually caution against the dangers posed by the high intensity of these sources. Therefore, waveguide optics are required. In [13], it is suggested that the very nature of the point sources should, in fact, make them even easier to convert as compared to traditional intermediate size 
sources. This should be more so, especially with the emergency of inexpensive plastic waveguides.

Lifespans of incandescent lamps average about $800 \mathrm{~h}$. Independent researchers have pegged the 50\% lumen depreciation lifespan of a white LED to a more realistic figure of $6000 \mathrm{~h} \mathrm{[8],}$ [9]. This is a far cry from the manufacturers' frequent claims of $100000 \mathrm{~h}$, which is probable when the LED finally shuts down. It is nonetheless far superior to the incandescent lamp and matches the CFLs, while at the same time not being completely out. (CFLs have additional shortcomings like disposal.) This gives an 8:1 advantage of cost over lifespan of the white LED against the incandescent lamp. It means that everytime one buys an LED lamp, one requires to buy at least eight incandescent lamps to last as long, giving a much better cost-effectiveness scenario in favor of the LED. It also means that even at the projected lowerend value of $50 \mathrm{~lm} / \mathrm{W}$ the LED will be far more cost effective to buy than the incandescent lamp while LED power consumption will be less than a third of that of an incandescent lamp.

At the current levels of technology the white LED's advantage over the incandescent lamp would appear to be mainly in task applications, like reading, and perhaps, for the use in kitchen. Additionally, when considering lumen depreciation (also called light-loss factor (LLF)), the LED scores yet another point. Because the reflectance of the reflector also deteriorates, the incandescent lamp has two depreciation factors to contend with, against the LED's one. Otherwise, with virtually the same efficacies elsewhere in the rural household, power consumption levels are matched.

Consider a rural African household comprised of two bedrooms, a kitchen, a bathroom with a toilet, and a lounge/dinning at the far end. One may assume over $80 \%$ of the full lighting load for the $4 \mathrm{~h}$ per evening and only incandescent lamps in use. Assume also that the room sizes and surrounding wall reflectances are such that specified lux levels can be achieved using $60 \mathrm{~W}$ in the kitchen, $40 \mathrm{~W}$ in each of the bedrooms, $25 \mathrm{~W}$ in the bathroom, $60 \mathrm{~W}$ for ambience in the lounge/dinning room, and an additional $20 \mathrm{~W}$ for the table reading lamp. The total peak load would be $225 \mathrm{~W}$. If CFL with average efficacy of $50 \mathrm{~lm} / \mathrm{W}$ were used, then, the total consumption would be $67.5 \mathrm{~W}$. An incandescent light and a CFL radiate light in all directions as well.

If white LEDs were used they would have a directivity advantage. Assuming a collective projected LED beam angle from the sealing of $120^{\circ}$, its approximate solid beam angle would then be $2 \pi\left(1-\cos \frac{\theta}{2}\right)=2 \pi(1-\cos 60)=\pi$ steradians [16], [17]. But a sphere is $4 \pi$ steradians. Therefore, the white LEDs are only required to supply one quarter of the lighting power. If the efficacy of the white LEDs were $15 \mathrm{~lm} / \mathrm{W}$ their peak power consumption would be $225 / 4=56 \mathrm{~W}$. But the white LEDs efficacy is currently (2003) of the order of $25 \mathrm{~lm} / \mathrm{W}$. Therefore, the consumption drops to

$$
\left[\frac{56}{25} \times 15\right]=33.6 \mathrm{~W} \text {. }
$$

If one should consider the same white LED having evolved to efficacy levels of $120 \mathrm{~lm} / \mathrm{W}$, then, the average load would become $(56 \times$ incandescent efficacy)/(LED efficacy).

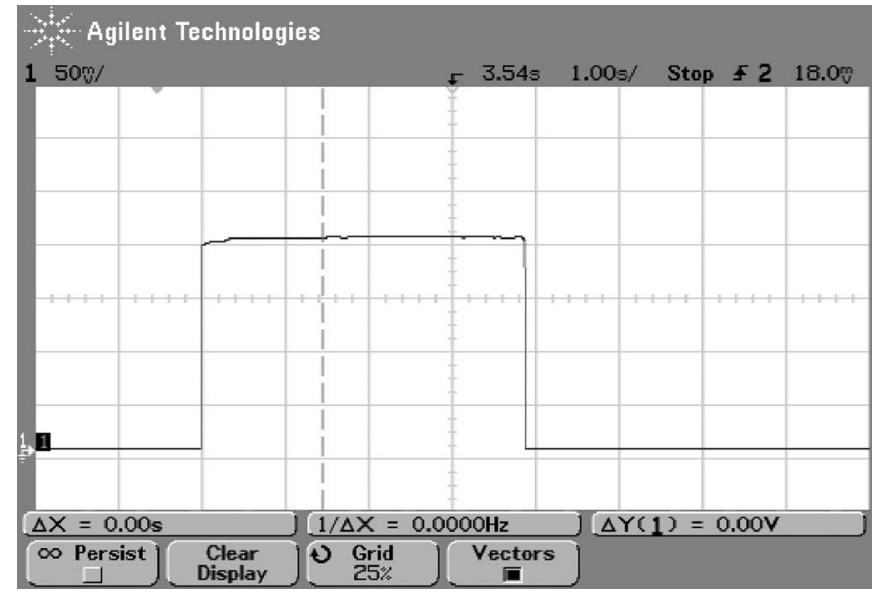

Fig. 6. Plot of a transient loading of a string of LEDs at $20 \mathrm{~mA}$.

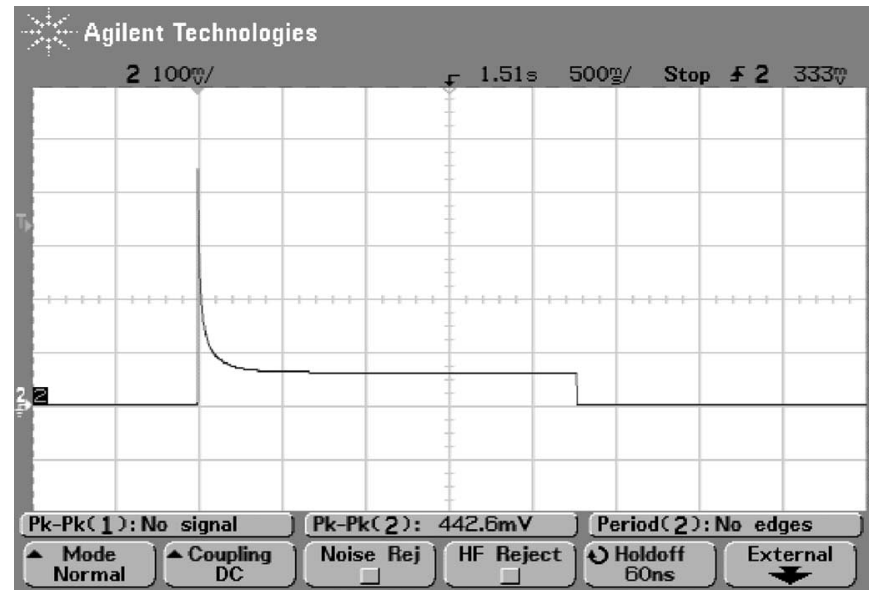

Fig. 7. Response of an incandescent lamp to a step input voltage.

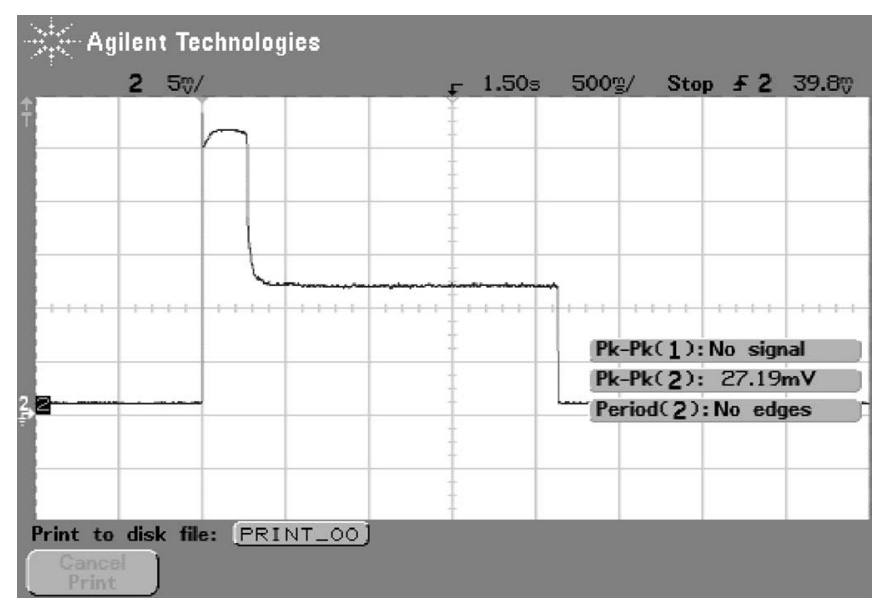

Fig. 8. Response of a fluorescent tube light to a step input voltage.

Peak load demand per household $=(56 \times 15) / 120=7 \mathrm{~W}$. For a village of 40 similar households, the maximum noncoincident electricity demand due to lighting would be $280 \mathrm{~W}$. 


\section{TRANSIENT LOADING}

A series of tests were carried out on various lighting loads to establish their transient responses to step input voltages. The response (on and off) of a series string of LEDs (with a current limiting resistor) is illustrated Fig. 6. The load current was $20 \mathrm{~mA}$ and measurements were taken using a 100-MHz scope. It would appear from these results that the response of an LED load to a step input voltage is a near replica of the response of an ideal resistor with no traceable transient overshoot. This exerts minimal stress on the power source. This can be contrasted with Figs. 7 and 8 for an incandescent lamp and a fluorescent tube light, respectively, which have high magnitudes of starting currents.

\section{CONCLUSION}

With such meager resources conservation is the only option. The white LED energy saving potential has been demonstrated even in its present form. It is the most suitable choice for rural lighting. This should be supported with sound illumination technology.

\section{APPENDIX}

CRI is a relative scale from $0-100$ and determines how colors of an object are perceived under an artificial light as compared to a reference light. The low-pressure sodium lamp, for example, while reputed to have the highest efficacy figures of the order of $130-150 \mathrm{~lm} / \mathrm{W}$, has a CRI of nearly zero. So, it can only be said to be efficient for the outdoors and certainly, very inefficient for indoors, as most colors appear black under this light. The incandescent lamp, on the other hand, has a very high CRI of nearly 100. Or put simply, colors appear most agreeable under light from an incandescent bulb. This could partly explain why even people who are clearly aware of relative lamp performances, energy benefits and those who can afford the "better" types (like CFLs) still keep choosing incandescent lamps. The current white LEDs perform very well with a CRI of 85 , which matches the compact fluorescents, (CFLs) and they will get better. Besides, CFLs use toxic mercury to function and their disposal is a problem.

Lumen depreciation is the reduction in output lumens of a light source with age. The depreciation rate is dependent on lamp type, environment, and rate of usage. The lifespan of a light source is deemed to have ended if the amount of lumens falls below $50 \%$ of the initial figure. "In lighting design we must take into account this fall by use of a maintenance factor." [3] This is one piece of data that is frequently a subject of distortion by manufacturers. The fact that $1 \mathrm{~m} / \mathrm{W}$ values on the labels are only valid for new lamps is hardly ever mentioned. However, considering this omission as a constant across the board, LEDs have relatively far longer lifespans than any other type.

\section{REFERENCES}

[1] Lighting Education (1983-1989), CIE Standard 99-1992.

[2] Lighting of Indoor Work Places, CIE Standard S008/E-2001.

[3] Maintenance of Indoor Electric Lighting Systems, CIE Standard 97-1992.

[4] Discomfort Glare in Interior Lighting, CIE Standard 117-1995.
[5] Proceedings of the First CIE Symposium on Lighting Quality. Vienna, Austria: CIE, 1998.

[6] Interior Lighting (Part 1: Artificial Lighting of Interiors), South African Bureau of Standards, SABS 0114-1, 1996.

[7] Interior Lighting (Part 2: Emergency Lighting), South African Bureau of Standards, SABS 0114-2, 2002.

[8] N. Narendran et al., "Characterizing white LEDs for general illumination applications," Proc. SPIE, vol. 3938, pp. 240-248, 2000.

[9] - "What is useful life for white light LEDs?," J. Illum. Eng. Soc., vol. 30 , no. 1 , p. 57,2001

[10] Operational Considerations for LED Lamps and Display Devices, Application note 1005, Agilent Technologies, Palo Alto, CA, 1999.

[11] Commission Internationale de L'Eclairage [Online]. Available: http:// vi12n153.members.eunet.at/cie/

[12] T. Makia and S. Nakamura, "White and UV LEDs," Oyo Buturi, vol. 68 no. 2, pp. 152-155, 1999.

[13] Light Emitting Diodes (LEDs) for General Illumination (An OIDA Technology Road Map Update), Sandia National Lab., Livermore, CA, 2002.

[14] T. Drennen, R. Haitz, and J. Tsao, "A market diffusion and energy impact model for solid-state lighting SAND2001-2830," presented at the 21st Annu. North Amer. Conf. U.S. Assoc. Energy Econ. Int. Assoc. Energy Econ., Philadelphia, PA, Sep. 2000.

[15] Arthur D. Little, Inc, "Energy saving potential of solid state lighting in general light applications," U.S. Department of Energy, Springfield, VA.

[16] D. Gibson, "Candlepower," CREG J., vol. 26, p. 27, Dec. 1996.

[17] Light emitting diode (IRED) power output specifications. Honeywell application note, Honeywell Sensing and Control, Freeport, IL, pp. 348349, [Online]. Available: http://content.honeywell.com/sensing/prodinfo/ infrared/application/In1eng.pdf

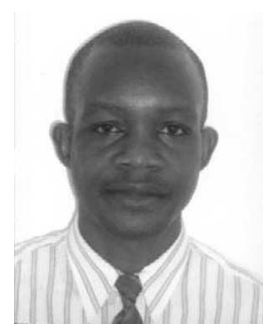

Adoniya Ben Sebitosi (S'03-M'04) received the B.Sc. degree from the University of Nairobi, Nairobi, Kenya, in 1977, and the M.Sc. and Ph.D. degrees from the University of Cape Town, Rondebosch, South Africa, in 2001 and 2004, respectively, all in electrical engineering.

He was an Instrumentation Calibration Engineer with Rohde and Schwarz International, Nairobi. In 1981, he was a Technical Manager with J.K. Industries, Ltd. From 1985 to 2000, he was a Service Engineer, and then, an Eastern Africa Regional Technical Instructor with Domino Amjet UK, Nairobi (Spicers East Africa, Ltd.). His current research interests include off-grid and rural energization renewable energy and energy conservation technologies. Since 2005, he has been a Research Officer and Lecturer in the Department of Electrical Engineering, University of Cape Town.

Dr. Sebitosi is a member of the Institution of Engineers of Kenya and a member of the Institution of Engineering and Technology (IET), London, U.K. $\mathrm{He}$ is a Chartered Engineer and a Registered Engineer in Kenya.

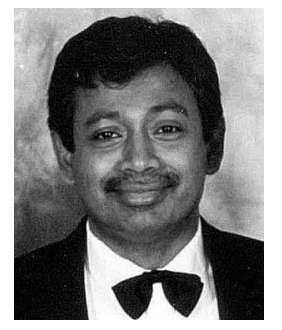

Pragasen Pillay (S'84-M'87-SM'92-F'05) received the Bachelor's degree from the University of Durban-Westville, Durban, South Africa, in 1981, the Master's degree from the University of Natal, Durban, South Africa, in 1983, and the Ph.D. degree from Virginia Polytechnic Institute and State University, Blacksburg, VA, in 1987, all in electrical engineering.

From January 1988 to August 1990, he was with the University of Newcastle, upon Tyne, Newcastle, U.K. From August 1990 to August 1995, he was with the University of New Orleans. Currently he is a Professor in the Department of Electrical and Computer Engineering, Clarkson University, Potsdam, NY, where he holds the Jean Newell Distinguished Professorship in Engineering. He has organized and taught short courses in electric drives at the Annual Meeting of the Industry Applications Society. His current research interests include modeling, designing, and control of electric motors and drives for industrial and alternate energy applications.

Dr. Pillay is a member of the Power Engineering, Industry Applications, Industrial Electronics, and Power Electronics Societies. He is a member of the Electric Machines Committee, past Chairman of the Industrial Drives in the Industry Applications Society, and Chairman of Induction Machinery Sub-Committee in the Power Engineering Society. He is a member of the Institution of Electrical Engineers, London, U.K., and a Chartered Electrical Engineer. 